See discussions, stats, and author profiles for this publication at: https://www.researchgate.net/publication/337171468

\title{
Normative scores of the Wisconsin Card Sorting Test in a sample of the adult Portuguese population
}

Article in Applied Neuropsychology: Adult · September 2020

Dol: 10.1080/23279095.2020.1810040

\section{CITATIONS}

3 authors:

Bruno Faustino

University of Lisbon

51 PUBLICATIONS 120 CITATIONS

SEE PROFILE

Paulo Jorge Ferreira Lopes

Universidade Lusófona de Humanidades e Tecnologias

63 PUBLICATIONS 471 CITATIONS

SEE PROFILE

Some of the authors of this publication are also working on these related projects:

Project Health Literacy Survey 19 View project

Anthropology-Based Computing View project

\section{READS}

64

Jorge Oliveira

Universidade Lusófona de Humanidades e Tecnologias

109 PUBLICATIONS 961 CITATIONS

SEE PROFILE 


\section{Normative scores of the Wisconsin Card Sorting Test in a sample of the adult Portuguese population}

\section{Bruno Faustino, Jorge Oliveira \& Paulo Lopes}

To cite this article: Bruno Faustino , Jorge Oliveira \& Paulo Lopes (2020): Normative scores of the Wisconsin Card Sorting Test in a sample of the adult Portuguese population, Applied Neuropsychology: Adult

To link to this article: https://doi.org/10.1080/23279095.2020.1810040

曲 Published online: 08 Sep 2020.

Submit your article to this journal $\asymp$

Q View related articles ¿

View Crossmark data $\nearrow$ 


\title{
Normative scores of the Wisconsin Card Sorting Test in a sample of the adult Portuguese population
}

\author{
Bruno Faustino $^{\mathrm{a}}\left(\mathbb{D}\right.$, Jorge Oliveira ${ }^{\mathrm{b}}\left(\mathbb{D}\right.$, and Paulo Lopes ${ }^{\mathrm{b}}$ \\ ${ }^{a}$ Department of Cognitive, Behavioral and Integrative Psychotherapy, Faculty of Psychology, University of Lisbon, Lisboa, Portugal; \\ ${ }^{b}$ Department of Psychology, School of Psychology and Life Sciences, University Lusófona de Humanidades e Tecnologias/HEl-Lab, \\ Lisboa, Portugal
}

\begin{abstract}
Objectives: The Wisconsin Card Sorting Test (WCST) is a neuropsychological instrument that is widely used for assessment of executive functioning in both clinical and research settings. The aim of this study was to provide the normative scores for the WCST in a sample of Portuguese healthy adults.

Methods: The data was collected from archival data in a total sample of 359 individuals, 149 men $(41.5 \%$, Mage $=38.3 ; S D=20.3)$ and 210 women (58.5\%, Mage = 52.2; SD=19.4). Descriptive statistics were calculated to describe mean scores, standard-deviation and percentiles of the WCST indexes by gender, age and education. ANOVAs were used to explore the differences between these scores in sociodemographic variables. The normative scores were adjusted for age and educational level.

Results: Significant statistical differences in mean scores were found in several WCST indexes, such as, total errors, perseverations, perseverative errors and conceptual level responses regarding age and education. Percentiles for WCST indexes were stratified by age group and educational level.

Conclusions: Age and education are important factors explaining performance on the WCST. This is the first study focused on the development of WCST normative scores for the adult Portuguese population, which can be applied in clinical, educational and research contexts.
\end{abstract}

\section{KEYWORDS}

Healthy adults; normative scores; Wisconsin Card

Sorting Test

\section{Introduction}

The Wisconsin Card Sorting Test (WCST) is a widely used neuropsychological assessment instruments to evaluate executive functions. Specifically, the WCST allows the assessment of the ability to generate, modify and apply a cognitive strategy in response to changing environmental contingencies (Berg, 1948; Grant \& Berg, 1948; Heaton et al., 2005; Kopp et al., 2019). Adequate performance in this test relies on cognitive operations such as planning, systematic searching and updating cognitive sets based on external feedback with inhibition of preponderant responses (Heaton et al., 2005; Kopp et al., 2019). These processes belong to the domain of executive functions, which is a broader conceptualization for higher-order executive process (Diamond, 2013), associated with goal-directed behavior (Friedman \& Miyake, 2017; Lezak et al., 2012).

Experimental and clinical neuropsychological research show that individuals with impaired performance on the WCST is associated with Dysexecutive Syndrome (DES), which is a cluster of symptoms typically related to brain impairment (Baddeley \& Wilson, 1988; Halligan et al., 2004). DES is described as a pattern of dysfunction in cognitive flexibility, abstract reasoning, working memory, decision making, planning, problem solving and behavioral regulation, being also defined as frontal lobe dysfunction (Wilson et al., 1998). However, recent evidence showed that DES is related to a widespread cortical and subcortical neural network (Eling et al., 2008; Nyhus \& Barceló, 2009). Accordingly, the WCST performance is now attributed to multiple interconnected brain networks rather than a single structure as the frontal lobes (Eling et al., 2008; Lezak et al., 2012; Nyhus \& Barceló, 2009; Strauss et al., 2006). The scientific debate is still underway due to the centrality of the frontal lobes in psychological process and specifically in executive functions (Kopp, Lange, et al., 2019; Miller \& Cummings, 2018; Snyder, 2013; Stuss \& Alexander, 2007).

Moreover, meta-analytic studies WCST performance deficits in psychiatric disorders, such as depression (Snyder, 2013), eating disorders (Roberts et al., 2007), obsessive-compulsive disorder (Shin et al., 2014) and attention deficit hyperactivity disorder (Romine et al., 2004), or neurological disorders, such as primary dystonia (Lange et al., 2016), amyotrophic lateral sclerosis (Lange et al., 2016) and Gilles de la Tourette (Lange et al., 2017). Even in low-powered or clinical studies, WCST deficits are described in dissociative disorders (Parlar et al., 2016; Prentice et al., 2008), depression (Gałecki et al., 2015; Rady et al., 2012), bipolar disorder 
(Fleck et al., 2008) alcohol use disorder (Spinola et al., 2017) and cocaine use disorder (Woicik et al., 2011).

In clinical settings, neuropsychological assessment by the WCST is based on the comparison of patient's performance with a standardized score or percentile, which allow to determine whether performance is higher or below the average of his/her normative group (Lezak et al., 2012). Previous studies showed that the WCST is sensitive to cultural differences in most WCST indexes, such as the number of trials administered, correct responses, total number of errors or perseverative responses (Coffey et al., 2005; Kohli \& Kaur, 2006; Shan et al., 2008), which highlight the need to provide the normative scores for the WCST for different cultural backgrounds. The normative scores for the WCST can be found for different countries, such as China (Shan et al., 2008), India (Kohli \& Kaur, 2006), North America (Heaton et al., 2005), Brazil (Trentini et al., 2010), Lebanon (Rammal et al., (2019), Argentina (Miranda et al., 2019) and Italy (Laiacona et al., 2000). However, the normative scores for the Portuguese population are still lacking.

Moreover, the role of sociodemographic variables on WCST performance are not fully understood. For instance, gender differences are not consistent (e.g. Heaton et al., 2005; Laiacona et al., 2000; Miranda et al., 2019), but Boone et al. (1993) found that female participants had better performance in the trials administered, total errors, perseverative responses, perseverative errors, conceptual level responses, categories completed and trials to complete first category. These differences were found in only middle to old age female participants. However, gender differences in executive functions are not consistent across studies, being probably related to sample bias or systematic error due to assessment instruments or the experimental tasks used in such studies (Grissom \& Reyes, 2019; Mitrushina et al., 2005).

The relationships of age and education variables with WCST performance are documented in different studies (e.g. Ashendorf \& McCaffrey, 2008; Fristoe et al., 1997; Heaton et al., 2005; Kohli \& Kaur, 2006; Miranda et al., 2019; Mitrushina et al., 2005; Rammal et al., 2019; Rhodes, 2004; Stratta et al., 2001). Thus, executive functions may be sensitive to aging process, and to formal education possibly being explained by cognitive reserve (Roldán-Tapia et al., 2012), which impact on WCST performance (Lázaro et al., 2011; Rhodes, 2004). Younger individuals tend to have higher performance in efficient responses (e.g. correct responses) and lower performance in non-efficient responses (e.g. total errors, perseverations) (Miranda et al., 2019; Rammal et al., 2019; Rhodes, 2004). Older adults with lower education reveal poorer performance in tasks of executive functioning (Martins et al., 2013). A similar effect may be described for education level, where individuals with higher education levels tend to have better performances in WCST (Boone et al., 1993; Heaton et al., 2005; Miranda et al., 2019; Shan et al., 2008). This effect tends to be more robust in the number of categories completed and perseverative errors in older individuals with less than 12 years of education (Rhodes, 2004).

There are several studies reporting the normative scores and the psychometric properties of the WCST for different countries. However, in Portugal the use of the WCST for clinical and research purposes is limited due to the absence of normative scores for this country. Therefore, this study aimed to provide the normative scores for the WCST according to a sample of the adult Portuguese population.

\section{Method}

\section{Participants and procedure}

The sample for this study was collected from control groups of different research projects in Portugal. The selection criteria for inclusion in the study were: (a) age above 18 years; (b) Portuguese nationality and living in Portugal for more than five years; (c) no psychiatric/neurological disorders. All participants gave informed consent for participation in a research study.

The total sample for this study consisted of 359 individuals (men $41.5 \%)$. The average age was 55 years $(S D=15.1)$ ranging from 18 to 90 years. The sample was stratified by sociodemographic characteristics as age, gender, and education. We divided our sample in the following groups: $<6$ years, 7-11 years and $>12$ years of education to have more balanced groups in terms of the number of cases. Years of formal education are defined by the number of years that individuals have attended formal education, namely, elementary, secondary, or higher education/university. Participants were divided into three age-groups according to Whitley et al. (2016) patterns of cognitive aging, specifically in three groups: 18-40 years old, 41-65 years old, and $66-90$ years old (Table 1).

Table 1. Sociodemographic description $(N=359)$.

\begin{tabular}{|c|c|c|c|c|c|c|c|c|}
\hline & \multicolumn{2}{|c|}{ Total sample $(n=359)$} & \multicolumn{2}{|c|}{$18-40$ Years old $(n=136)$} & \multicolumn{2}{|c|}{$41-65$ Years old $(n=110)$} & \multicolumn{2}{|c|}{$66-90$ Years old $(n=113)$} \\
\hline & $n$ & $\%$ & $n$ & $\%$ & $n$ & $\%$ & $n$ & $\%$ \\
\hline \multicolumn{9}{|l|}{ Gender } \\
\hline Men & 149 & 41.5 & 65 & 47.8 & 41 & 37.3 & 43 & 38.1 \\
\hline Women & 210 & 58.5 & 71 & 52.2 & 69 & 62.7 & 70 & 61.9 \\
\hline \multicolumn{9}{|l|}{ Educational Level } \\
\hline$<6$ years & 123 & 34.2 & 20 & 14.75 & 32 & 29.1 & 71 & 62.8 \\
\hline $7-11$ years & 95 & 26.5 & 39 & 28.7 & 36 & 32.7 & 20 & 17.7 \\
\hline$>12$ years & 141 & 39.3 & 77 & 21.4 & 42 & 38.2 & 22 & 19.5 \\
\hline \multicolumn{9}{|l|}{ Occupation } \\
\hline Employed & 204 & 56.8 & 115 & 84.6 & 81 & 73.6 & 8 & 71 \\
\hline Unemployed & 23 & 6.4 & 11 & 8.1 & 12 & 10.9 & 0 & 0 \\
\hline Retired & 120 & 33.4 & 0 & 0 & 15 & 13.6 & 105 & 87.5 \\
\hline Unknown & 12 & 3.3 & 10 & 7.4 & 2 & 1.8 & 0 & 0 \\
\hline
\end{tabular}


The analysis on these data was approved by the ethics committee of the host institution of this study. All procedures performed in studies involving human participants were in accordance with the ethical standards of the institutional and/or national research committee and with the 1964 Helsinki declaration and its later amendments or comparable ethical standards.

\section{Measures}

\section{Wisconsin Card Sorting Test}

The Wisconsin Card Sorting Test (WCST) is a test developed to assess executive functions (Berg, 1948, Heaton et al., 2005) consisting of four target cards and 128 response cards. Each card represents different forms (crosses, circles, triangles, or stars), colors (green, yellow, blue and red) and number of figures (one, two, three or four figures). The task is to match (color, shape, or number) each card from a deck of 128 cards that are provided to the participant one by one to the target cards. The WCST is scored on eleven performance parameters, namely: trials administered; correct responses; total errors; perseverative responses; perseverative errors; non-perseverative errors; conceptual level responses; categories completed; trials to complete first category; failure to maintain set and other responses. Raw scores were used in statistical analysis. WCST was administered according to the standards provided in the manual of Heaton and colleagues (2005).

\section{Statistical analysis}

The data processing and statistical analysis was conducted with the Statistical Package for the Social Sciences (IBM SPSS Statistics, version 24.0 for Windows). Normal distribution was assumed $(N>30)$, and multicollinearity was analyzed and showed to be adequate for all statistical procedures (Pallant, 2007). Descriptive analysis and WCST normative scores based on mean values, standard deviation and percentiles were performed. To explore the differences in mean scores between groups for the performance indicators of the WCST in sociodemographic variables as gender, age, and education, different Analyses of Variance (ANOVA), were performed. Post-hoc analyses with
Bonferroni correction were used to explore further the differences between these groups.

\section{Results}

The sample comprised 149 men (41.5\%) and 210 women $(58.5 \%), 123$ with <6years of study (34.2\%), 95 with $7-11$ years of study $(26.5 \%)$ and 141 with $>12$ years $(39.3 \%)$. Regarding professional occupation, 204 were employed $(56.8 \%), 23$ were unemployed (6.4\%), 120 were retired (33.4\%) and 12 did not described any occupation $(3.3 \%)$, as depicted in Table 1.

Table 2 describes the comparisons between categories for gender, age groups and level of education. The alpha level was set at .05 for significant tests. A statistically significant difference between gender was found only in conceptual level responses $(F=4.840, p=.020)$. Regarding age groups, the younger group had lower scores comparing to middle-age and older groups in trials administered $(F=35.023$, $p<.001)$, total errors $(F=54.896, p<.001)$, perseverations $(F=51.152, \quad p<.001)$, perseverative errors $(F=52.812$, $p<.001)$ and non-perseverative errors $(F=12.994, p<.001)$, which is consistent with the observed pattern, revealing a relationship of age in WCST performance. In the trials to complete first category, there were no differences between the younger and the middle-age group, but both groups were statistically different from the older group $(F=15.734$, $p<.001)$. In conceptual level responses, the middle group had higher scores than the other two groups $(F=14.960, p<.001)$.

Regarding education, significant differences were found between age groups in most of WCST indexes $(p<.001)$. Individuals with lower education ( $<6$ years) had consistently higher scores in total errors $(\mathrm{F}=71.318, \mathrm{p}<.001)$, and preservations $(\mathrm{F}=69.388, \mathrm{p}<.001)$, and lower scores in conceptual responses $(\mathrm{F}=18.745, \mathrm{p}<.001)$, and categories completed $(\mathrm{F}=59.219, \mathrm{p}<.001)$, that the middle $(7-11$ years) and higher education ( $>12$ years) groups. However, in the failure to maintain set and other responses indexes, differences were not significant.

The normative data are described in Table 3. Poorer performance was observed with increasing age. Regarding the comparisons between education levels by age groups, higher education was associated with better performance in most of

Table 2. Means and standard deviations of WCST indexes for healthy Portuguese individuals $(N=359)$.

\begin{tabular}{|c|c|c|c|c|c|c|c|c|c|}
\hline \multirow[b]{2}{*}{ WCST indexes } & \multicolumn{3}{|c|}{ Gender } & \multicolumn{3}{|c|}{ Age group } & \multicolumn{3}{|c|}{ Education level } \\
\hline & $F$ & $p$ & $B C$ & $F$ & $p$ & $B C$ & $F$ & $p$ & $B C$ \\
\hline Trials administered & 0.040 & 0.84 & $\mathrm{~W}=\mathrm{M}$ & 35.023 & 0.00 & $\mathrm{Y}<\mathrm{M}<\mathrm{O}$ & 36.916 & 0.00 & $\mathrm{~L}>\mathrm{Me}>\mathrm{H}$ \\
\hline Correct responses & 0.521 & 0.47 & $\mathrm{~W}=\mathrm{M}$ & 19.348 & 0.00 & $\mathrm{Y}<\mathrm{M}>0$ & 24.233 & 0.00 & $\mathrm{~L}<\mathrm{Me}=\mathrm{H}$ \\
\hline Total errors & 0.020 & 0.88 & $\mathrm{~W}=\mathrm{M}$ & 54.896 & 0.00 & $\mathrm{Y}<\mathrm{M}<\mathrm{O}$ & 71.318 & 0.00 & $\mathrm{~L}>\mathrm{Me}>\mathrm{H}$ \\
\hline Perseverations & 0.058 & 0.80 & $\mathrm{~W}=\mathrm{M}$ & 51.152 & 0.00 & $\mathrm{Y}<\mathrm{M}<\mathrm{O}$ & 69.388 & 0.00 & $\mathrm{~L}>\mathrm{Me}=\mathrm{H}$ \\
\hline Perseverative errors & 0.042 & 0.83 & $\mathrm{~W}=\mathrm{M}$ & 52.812 & 0.00 & $\mathrm{Y}<\mathrm{M}<\mathrm{O}$ & 72.730 & 0.00 & $\mathrm{~L}>\mathrm{Me}=\mathrm{H}$ \\
\hline Non-perseverative errors & 0.730 & 0.39 & $\mathrm{~W}=\mathrm{M}$ & 12.994 & 0.00 & $\mathrm{Y}<\mathrm{M}<\mathrm{O}$ & 15.195 & 0.00 & $\mathrm{~L}=\mathrm{Me}>\mathrm{H}$ \\
\hline Conceptual level responses & 4.840 & 0.02 & $W>M$ & 14.960 & 0.00 & $\mathrm{Y}<\mathrm{M}>0$ & 18.745 & 0.00 & $\mathrm{~L}<\mathrm{Me}<\mathrm{H}$ \\
\hline Categories completed & 0.015 & 0.90 & $\mathrm{~W}=\mathrm{M}$ & 51.076 & 0.00 & $\mathrm{Y}>\mathrm{M}>0$ & 59.219 & 0.00 & $\mathrm{~L}<\mathrm{Me}=\mathrm{H}$ \\
\hline Trials to complete 1 st category & 2.394 & 0.12 & $\mathrm{~W}=\mathrm{M}$ & 15.734 & 0.00 & $\mathrm{Y}=\mathrm{M}<\mathrm{O}$ & 15.028 & 0.00 & $\mathrm{~L}>\mathrm{Me}=\mathrm{H}$ \\
\hline Failure to maintain set & 0.883 & 0.34 & $\mathrm{~W}=\mathrm{M}$ & 3.564 & 0.02 & $\mathrm{Y}<\mathrm{M}>0$ & 0.062 & 0.94 & $\mathrm{~L}=\mathrm{Me}=\mathrm{H}$ \\
\hline Other responses & 0.681 & 0.42 & $\mathrm{~W}=\mathrm{M}$ & 0.177 & 0.84 & $\mathrm{Y}<\mathrm{O}$ & 0.126 & 0.88 & $\mathrm{~L}=\mathrm{Me}=\mathrm{H}$ \\
\hline
\end{tabular}

W: women; $M$; men; $Y=18-40 ; M=41-65 ; O=65-90 ; L=<6$ years; $M e=7-11$ years; $H=12<; B c$ : Bonferroni Correction. 


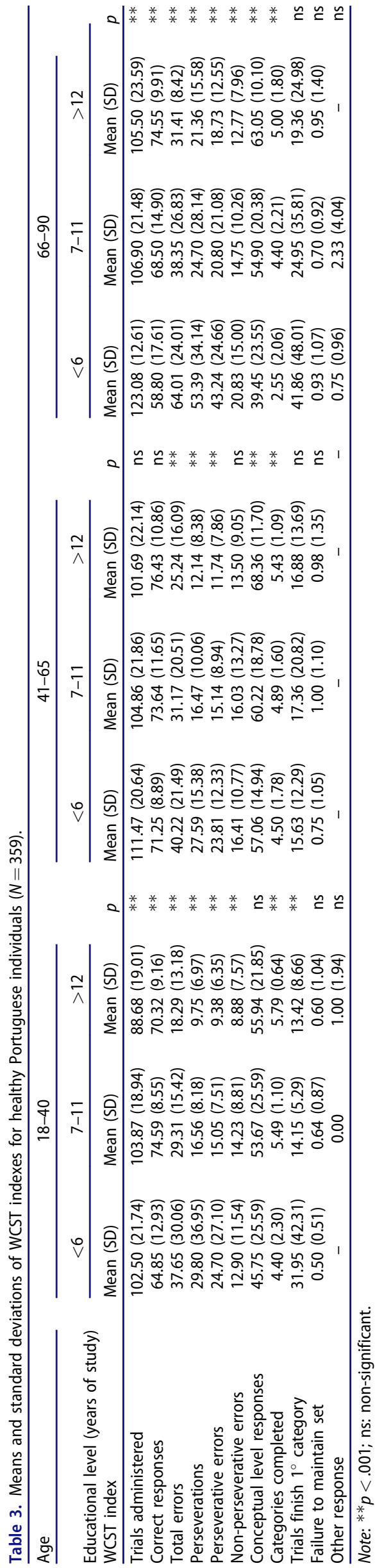

WCST indexes in the three age groups. In the 18-40 years old interval group, significant differences were found in trials administered $(F=9.664, p<.001)$, correct responses $(F=6.932, p<.001)$, total errors $(F=12.368, p<.001)$, perseverations $(F=13,602, \quad p<.001), \quad$ perseverative errors $(F=13.542, \quad p<.001)$, non-perseverative errors $(F=5.574$, $p<.005)$, categories completed $(F=11.550, p<.001)$, and trials finish $1^{\circ}$ category $(F=9.326, p<.001)$.

In the 41-65 years old interval group, the association of higher education was statistically significant in total errors $(F=5.508, \quad p<.005)$, perseverations $(F=17.377, \quad p<.001)$, perseverative errors $(F=14.538, \quad p<.001)$, conceptual level responses $(F=5.534, p<.005)$ and categories completed $(F=$ $3.657, p<.001)$.

Finally, in the 66-90 years old interval group, significant differences between levels of education were found in trials administered $(F=13.188, \quad p<.001), \quad$ correct responses $(F=9.331, p<.001)$, total errors $(F=20.833, p<.001)$, perseverations $(F=13.287, \quad p<.001)$, perseverative errors $(F=14.836, \quad p<.001)$, non-perseverative errors $(F=3.970$, $p<.001)$, conceptual level responses $(F=12.330, p<.001)$ and categories completed $(F=15.294, p<.001)$. Differences between levels of education were not significant in failure to maintain set at any age group. The other responses index did not have enough observations in the 41-65 years old interval group to perform this analysis. The performance percentiles for each WCST index are described in Table 4.

\section{Discussion}

Despite the WCST be one of the most used neuropsychological assessment instruments to assess executive functions, the normative scores for the adult Portuguese population are still lacking. Therefore, this study focused in providing the normative scores and percentiles of performance of the WCST for the Portuguese population. The results of this study are aligned with the results from other studies on the development of norms for the WCST (Heaton et al., 2005; Kohli \& Kaur, 2006; Miranda et al., 2019). Our results revealed that most of the WCST indexes are sensitive to sociodemographic variables, specifically, age and education. In contrast, gender differences were not found in most WCST indexes. Only for conceptual level responses that women had higher scores than men. Boone et al. (1993), found differences between men and women in WCST performance, but recent studies did not report gender differences on WCST performance (Miranda et al., 2019; Shan et al., 2008).

A significant relationship was found between age and performance in WCST performance, revealing poorer performance in this test with increasing age. This result is in line with previous literature, where age-related differences were found in WCST performance (Ashendorf \& McCaffrey, 2008; Fristoe et al., 1997; Heaton et al., 2005; Kohli \& Kaur, 2006; Miranda et al., 2019; Rhodes, 2004). A possible explanation may be related to the effects of brain aging in executive functioning. Despite recent discussions regarding neuroanatomical structures of executive functions 


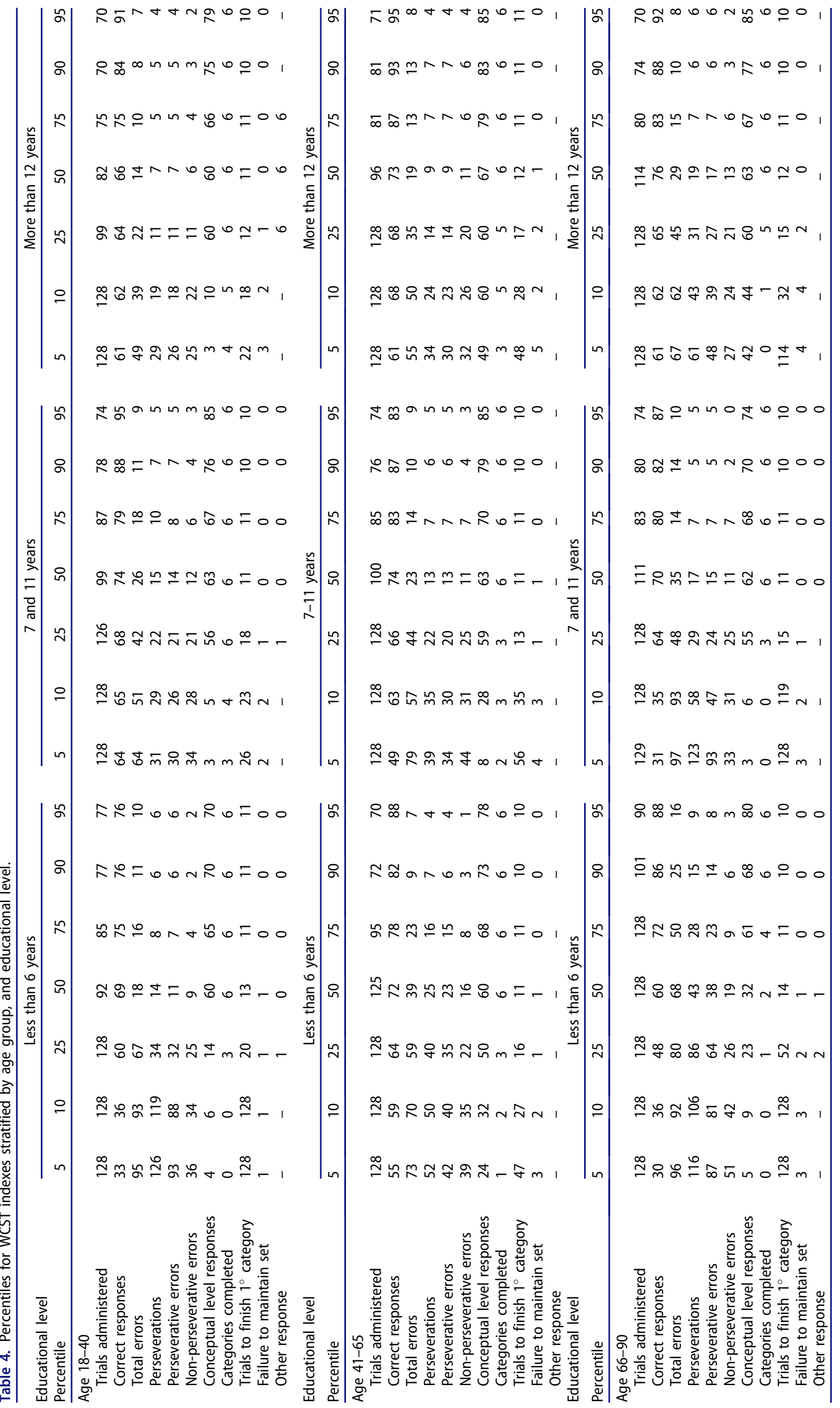


(Kopp et al., 2019; Miller \& Cummings, 2018; Nyhus \& Barceló, 2009; Snyder, 2013; Stuss \& Alexander, 2007), the prefrontal cortex is widely accepted as one of the major structures of the frontal lobe implicated on executive functioning (Miyake et al., 2000; Shimamura, 2000). The prefrontal cortex tends to deteriorate with age (Raz, 2000), which may help explaining an age-related decline in performance of this test (Rhodes, 2004). According to Ashendorf and McCaffrey (2008), poorer cognitive flexibility, perseveration, alongside with declines in working memory/speed of processing and inefficiency in using environmental feedback may contribute to explain the impacts of aging in WCST performance. Age-related changes in those cognitive processes might account for the observed differences in WCST performance by age groups.

Education level was also associated with WCST performance. Individuals with higher education group ( $>12$ years) had consistently better performance in WCST that lower education group ( $<6$ years). This is also in line with previous research (Boone et al., 1993; Heaton et al., 2005; Miranda et al., 2019; Rammal et al., 2019; Shan et al., 2008). However, differences were not found between middle education and higher education group in correct responses, total errors, perseverations, perseverative errors, categories completed, trials to complete first category, failure to maintain set and other responses. This result may imply that individuals with lower education levels may have more difficulties on the WCST task than individuals with middle education and higher education level. In this sense, formal education may have a positive role in the development of cognitive skills associated with the executive functions, being related with WCST performance (Heaton et al., 2005; Miyake et al., 2000; Miyake \& Friedman, 2012). Formal educational and contextual learning experiences may foster the development of executive functions, because of the increasing exposure to reading and verbal habits, visual and abstract reasoning exercises, mathematics and problem-solving tasks and metacognitive reflection (Lázaro et al., 2011).

However, these results should be interpreted with caution given the limitations related to the sample. It is worth noting that this study was conducted with archival data, which precluded the conduction of a prior power analysis. Thus, for the same reasons, it was not possible to ascertain temporal stability or to compute learning to learn index in the WCST. More research is required to explore in more depth the validity of WCST, specifically with clinical samples.

\section{Conclusions}

This is the first study focused on the development of normative scores for the WCST in the adult Portuguese population. These results highlight the association of age and education in WCST performance, which is in line with previous findings of the relationship between normal aging process and years of education in the executive functioning.

\section{Acknowledgments}

The authors have not received specific funding for this study.

\section{Disclosure statement}

No potential conflict of interest was reported by the author(s).

\section{ORCID}

Bruno Faustino (iD) http://orcid.org/0000-0002-7948-1622 Jorge Oliveira (iD http://orcid.org/0000-0002-3467-4981

Paulo Lopes (D) http://orcid.org/0000-0002-3128-1365

\section{References}

Ashendorf, L., \& McCaffrey, R. J. (2008). Exploring age-related decline on the Wisconsin Card Sorting Test. The Clinical Neuropsychologist, 22(2), 262-272. https://doi.org/10.1080/13854040701218436

Baddeley, A. D., \& Wilson, B. (1988). Frontal amnesia and the dysexecutive syndrome. Brain and Cognition, 7(2), 212-230. https://doi.org/ 10.1016/0278-2626(88)90031-0

Berg, E. A. (1948). A simple objective technique for measuring flexibility in thinking. The Journal of General Psychology, 39, 12-15. https://doi.org/10.1080/00221309.1948.9918159

Boone, K. B., Ghaffarian, S., Lesser, I. M., Hill-Gutierrez, E., \& G Berman, N. (1993). Wisconsin Card Sorting Test performance in healthy, older adults: Relationship to age, sex, education, and IQ. Journal of Clinical Psychology, 49(1), 54-60. https://doi.org/10.1002/ 1097-4679(199301)49:1<54::AID-JCLP2270490108>3.0.CO;2-6

Coffey, D. M., Marmol, L., Schock, L., \& Adams, W. (2005). The influence of acculturation on the Wisconsin Card Sorting Test by Mexican Americans. Archives of Clinical Neuropsychology: The Official Journal of the National Academy of Neuropsychologists, 20(6), 795-803. https://doi.org/10.1016/j.acn.2005.04.009

Diamond, A. (2013). Executive functions. Annual Review of Psychology, 64(1), 135-136. https://doi.org/10.1146/annurev-psych-113011-143750

Eling, P., Derckx, K., \& Maes, R. (2008). On the historical and conceptual background of the Wisconsin Card Sorting Test. Brain and Cognition, 67(3), 247-253. https://doi.org/10.1016/j.bandc.2008.01.00

Fleck, D. E., Shear, P. K., Madore, M., \& Strakowski, S. M. (2008). Wisconsin Card Sorting Test performance in bipolar disorder: effects of mood state and early course. Bipolar Disorders, 10(4), 539-545. https://doi.org/10.1111/j.1399-5618.2008.00582.x

Friedman, N. P., \& Miyake, A. (2017). Unity and diversity of executive functions: Individual differences as a window on cognitive structure. Cortex; a Journal Devoted to the Study of the Nervous System and Behavior, 86, 186-204. https://doi.org/10.1016/j.cortex.2016.04.023

Fristoe, N. M., Salthouse, T. A., \& Woodard, J. L. (1997). Examination of age-related deficits on the Wisconsin Card Sorting Test. Neuropsychology, 11(3), 428-436. https://doi.org/10.1037/0894-4105. 11.3.428

Gałecki, P., Talarowska, M., Anderson, G., Berk, M., \& Maes, M. (2015). Mechanisms underlying neurocognitive dysfunctions in recurrent major depression. Medical Science Monitor: International Medical Journal of Experimental and Clinical Research, 21, 1535-1547. https://doi.org/10.12659/MSM.893176

Grant, D. A., \& Berg, E. A. (1948). A behavioral analysis of degree of reinforcement and ease of shifting to new responses in a Weigl-type card-sorting problem. Journal of Experimental Psychology, 38(4), 404-411. https://doi.org/10.1037/h0059831

Grissom, N. M., \& Reyes, T. M. (2019). Correction: Let's call the whole thing off: evaluating gender and sex differences in executive function. Neuropsychopharmacology: Official Publication of the American College of Neuropsychopharmacology, 44(7), 1344. https://doi.org/10. 1038/s41386-019-0367-y

Halligan, P. W., Kischka, U., \& Marshall, J. C. (2004). Handbook of clinical neuropsychology. Oxford University Press. 
Heaton, R. K., Chelune, G. J., Talley, J. L., Kay, G. G., \& Curtiss, G. (2005). Teste Wisconsin de Classificação de Cartas: manual revisado e ampliado. Adaptação e padronização brasileira Jurema Alcides Cunha, Classira Trentini, Irani de Lima, Argimon, Margareth Oliveira, Blaca Weiang \& Rita Prieb. Casa do Psicólogo.

Kohli, A., \& Kaur, M. (2006). Wisconsin Card Sorting Test: normative data and experience. Indian Journal of Psychiatry, 48(3), 181-184. https://doi.org/10.4103/0019-5545.31582

Kopp, B., Lange, F., \& Steinke, A. (2019). The reliability of the Wisconsin Card Sorting Test in clinical practice. Assessment. https:// doi.org/10.1177/1073191119866257

Kopp, B., Steinke, A., Bertram, M., Skripuletz, T., \& Lange, F. (2019). Multiple levels of control processes for Wisconsin Card Sorts: An observational study. Brain Sciences, 9(6), 141. https://doi.org/10. 3390/brainsci9060141

Laiacona, M., Inzaghi, M. G., De Tanti, A., \& Capitani, E. (2000). Wisconsin card sorting test: a new global score, with Italian norms, and its relationship with the Weigl sorting test. Neurological Sciences: Official Journal of the Italian Neurological Society and of the Italian Society of Clinical Neurophysiology, 21(5), 279-291. https://doi.org/10.1007/s100720070065

Lange, F., Seer, C., Dengler, R., Dressler, D., \& Kopp, B. (2016). Cognitive flexibility in primary dystonia. Journal of the International Neuropsychological Society: JINS, 22(6), 662-670. https://doi.org/10. 1017/S135561771600045X

Lange, F., Seer, C., Müller-Vahl, K., \& Kopp, B. (2017). Cognitive flexibility and its electrophysiological correlates in Gilles de la Tourette syndrome. Developmental Cognitive Neuroscience, 27, 78-90. https:// doi.org/10.1016/j.dcn.2017.08.008

Lange, F., Vogts, M.-B., Seer, C., Fürkötter, S., Abdulla, S., Dengler, R., Kopp, B., \& Petri, S. (2016). Impaired set-shifting in amyotrophic lateral sclerosis: An event-related potential study of executive function. Neuropsychology, 30(1), 120-134. https://doi.org/10.1037/ neu0000218

Lázaro, J. C. F., Carrasco, B. T., \& Ruiz, B. C. (2011). Influencia del nivel y de la actividad escolar en las funciones ejecutivas. Interamerican Journal of Psychology, 45(2), 281-292.

Lezak, M. D., Howieson, D. B., Bigler, E. D., \& Tranel, D. (2012). Neuropsychological assessment (5th ed.). Oxford University Press.

Martins, I. P., Maruta, C., Freitas, V., \& Mares, I. (2013). Executive performance in older Portuguese adults with low education. The Clinical Neuropsychologist, 27(3), 410-412. https://doi.org/10.1080/ 13854046.2012.748094

Miller, B. L., \& Cummings, J. L. (2018). The human frontal lobes (2nd ed.). The Guidford Press.

Miranda, A. R., Sierra, J. F., Roulet, A. M., Rivadero, L., Serra, S. V., \& Soria, E. A. (2019). Age, education and gender effects on Wisconsin card sorting test: Standardization, reliability and validity in healthy Argentinian adults. Aging, Neuropsychology and Cognition. https:// doi.org/10.1080/13825585.2019.1693491

Mitrushina, M., Boone, K. B., Razani, J., \& D’Elia, L. F. (2005). Handbook of normative data for neuropsychological assessment (2nd ed.). Oxford University Press.

Miyake, A., \& Friedman, N. P. (2012). The nature and organization of individual differences in executive functions: four general conclusions. Current Directions in Psychological Science, 21(1), 8-14. https://doi.org/10.1177/0963721411429458

Miyake, A., Friedman, N. P., Emerson, M. J., Witzki, A. H., Howerter, A., \& Wager, T. D. (2000). The unity and diversity of executive functions and their contributions to complex "frontal lobe" tasks: A latent variable analysis. Cognitive Psychology, 41(1), 49-100. https:// doi.org/10.1006/cogp.1999.0734

Nyhus, E., \& Barceló, F. (2009). The Wisconsin Card Sorting Test and the cognitive assessment of prefrontal executive functions: a critical update. Brain and Cognition, 71(3), 437-451. https://doi.org/10. 1016/j.bandc.2009.03.005

Pallant, J. (2007). SPSS survival manual: A step by step guide to data analysis using SPSS for windows (Version 15). Open University Press, McGrow Hill Education.
Parlar, M., Frewen, P. A., Oremus, C., Lanius, R. A., \& McKinnon, M. C. (2016). Dissociative symptoms are associated with reduced neuropsychological performance in patients with recurrent depression and a history of trauma exposure. European Journal of Psychotraumatology, 7(1), 29061. https://doi.org/10.3402/ejpt.v7.29061

Prentice, K. J., Gold, J. M., \& Buchanan, R. W. (2008). The Wisconsin Card Sorting impairment in schizophrenia is evident in the first four trials. Schizophrenia Research, 106(1), 81-87. https://doi.org/10. 1016/j.schres.2007.07.015

Rammal, S., Chahine, S. J., Rammal, M., Fares, Y., \& Abbas, L. A. (2019). Modified Wisconsin Card Sorting Test (M-WCST): Normative data for the Lebanese adult population. Developmental Neuropsychology, 44(5), 397-408. https://doi.org/10.1080/87565641. 2019.1652828

Raz, N. (2000). Aging of the brain and its impact on cognitive performance: Integration of structural and functional findings. In F. I. M. Craik \& T. A. Salthouse (Eds.), The handbook of aging and cognition (p. 1-90). Lawrence Erlbaum Associates Publishers.

Rady, A., Elsheshai, A., Abou el Wafa, H., \& Elkholy, O. (2012). WCST performance in schizophrenia and severe depression with psychotic features. ISRN Psychiatry, 2012, 1-4. https://doi.org/10. $5402 / 2012 / 373748$

Rhodes, M. G. (2004). Age-related differences in performance on the Wisconsin Card Sorting Test: A meta-analytic review. Psychology and Aging, 19(3), 482-494. https://doi.org/10.1037/08827974.19.3.482

Roberts, M., Tchanturia, K., Stahl, D., Southgate, L., \& Treasure, J. (2007). A systematic review and meta-analysis of set-shifting ability in eating disorders. Psychological Medicine, 37(8), 1075-1084. https://doi.org/10.1017/S0033291707009877

Roldán-Tapia, L., García, J., Cánovas, R., \& León, I. (2012). Cognitive reserve, age, and their relation to attentional and executive functions. Applied Neuropsychology: Adult, 19(1), 2-8. https://doi.org/10. 1080/09084282.2011.595458

Romine, C. B., Lee, D., Wolfe, M. E., Homack, S., George, C., \& Riccio, C. A. (2004). Wisconsin Card Sorting Test with children: A meta-analytic study of sensitivity and specificity. Archives of Clinical Neuropsychology: The Official Journal of the National Academy of Neuropsychologists, 19(8), 1027-1041. https://doi.org/10.1016/j.acn. 2003.12.009

Shan, I. K., Chen, Y. S., Lee, Y. C., \& Su, T. P. (2008). Adult normative data of the Wisconsin Card Sorting Test in Taiwan. Journal of the Chinese Medical Association: JCMA, 71(10), 517-522. https://doi.org/ 10.1016/S1726-4901(08)70160-6

Shimamura, A. P. (2000). Toward a cognitive neuroscience of metacognition. Consciousness and Cognition, 9(2 Pt 1), 313-326. https://doi. org/10.1006/ccog.2000.0450

Shin, N. Y., Lee, T. Y., Kim, E., \& Kwon, J. S. (2014). Cognitive functioning in obsessive-compulsive disorder: A meta-analysis. Psychological Medicine, 44(6), 1121-1130. https://doi.org/10.1017/ S0033291713001803

Snyder, H. R. (2013). Major depressive disorder is associated with broad impairments on neuropsychological measures of executive function: A meta-analysis and review. Psychological Bulletin, 139(1), 81-132. https://doi.org/10.1037/a0028727

Spinola, S., Maisto, S. A., White, C. N., \& Huddleson, T. (2017). Effects of acute alcohol intoxication on executive functions controlling selfregulated behavior. Alcohol, 61, 1-8. https://doi.org/10.1016/j.alcohol.2017.02.177

Stratta, P., Prosperini, P., Daneluzzo, E., Bustini, M., \& Rossi, A. (2001). Educational level and age influence spatial working memory and Wisconsin Card Sorting Test performance differently: A controlled study in schizophrenic patients. Psychiatry Research, 102(1), 39-48. https://doi.org/10.1016/s0165-1781(01)00230-x

Strauss, E., Sherman, E. M. S., \& Spreen, O. (2006). A compendium of neuropsychological tests: Administration, norms, and commentary (3rd ed.). Oxford University Press

Stuss, D. T., \& Alexander, M. P. (2007). Is there a dysexecutive syndrome? Philosophical Transactions of the Royal Society of London. 
Series B, Biological Sciences, 362(1481), 901-915. https://doi.org/10. 1098/rstb.2007.2096

Trentini, C. M., Argimon, I. I. L., Oliveira, M. S., \& Werlang, B. S. G. (2010). O Teste Wisconsin de Classificação de Cartas: versão para idosos/adaptação e padronização brasileira. Casa do Psicólogo.

Whitley, E., Popham, F., \& Benzeval, M. (2016). Comparison of the Rowe-Kahn model of successful aging with self-rated health and life satisfaction: The west of Scotland Twenty- 07 prospective cohort study. The Gerontologist, 56(6), 1082-1092. https://doi.org/10.1093/ geront/gnv054
Wilson, B. A., Evans, J. J., Emslie, H., Alderman, N., \& Burgess, P. W. (1998). The development of an ecologically valid test for assessing patients with a dysexecutive syndrome. Neuropsychological Rehabilitation, 8(3), 213-228. https://doi.org/10.1080/713755570

Woicik, P. A., Urban, C., Alia-Klein, N., Henry, A., Maloney, T., Telang, F., Wang, G.-J., Volkow, N. D., \& Goldstein, R. Z. (2011). A pattern of perseveration in cocaine addiction may reveal neurocognitive processes implicit in the Wisconsin Card Sorting Test. Neuropsychologia, 49(7), 1660-1669. https://doi.org/10.1016/j.neuropsychologia.2011.02.037 